\title{
Medical Device Regulations: A Current Perspective
}

\author{
Sandeep Kumar Gupta
}

Department of Pharmacology, Dhanalakshmi Srinivasan Medical College and Hospital (DSMCH), Perambalur, Tamil Nadu-621212, India.

\begin{abstract}
There has been an upsurge in the number, diversity, and intricacy of medical devices in last two decades. Regulation of these devices has also advanced due to the requirement for a steady regulatory perspective. Various regulations of medical devices across major economies of the world were reviewed and then other pertinent issues of medical device regulations were discussed. The regulatory guidelines for medical devices in various countries which include United States, Europe, Japan, India, Brazil Japan, Australia etc. were reviewed. The need for harmonization of the device regulations and other regulatory issues were also assessed. Since the early 1980s, the regulatory paradigm for medical devices has changed exceptionally. Currently there are many countries which have enforced medical device regulations. Now with the availability of different regulations of the countries or region on medical devices, there is a need to harmonize regulations in order to curtail regulatory hurdles and expedite access to high quality, safe and efficacious medical devices. Most countries are trying to harmonize the regulatory guidelines for medical devices through their participation in Global Harmonization Task Force (GHTF).
\end{abstract}

Harmonized regulation of medical device will lead to the availability of quality product.

Key words: Medical device, Medical device recalls, Food drug and cosmetic act, Clinical trial, Humanitarian device exemption.

Key-message: The regulation of medical devices around the world is very diverse.Most countries are trying to harmonize the regulatory guidelines for medical devices through their participation in GHTF. Harmonized regulation of medical device will lead to the availability of quality product."

Correspondence :

Dr. Sandeep Kumar Gupta

Department of Pharmacology, Dhanalakshmi Srinivasan Medical College and Hospital (DSMCH), Perambalur, Tamil Nadu-621212, India.

E-mail: drsandeep_gupta@rediffmail.com

DOI : 10.5530/iyp.2016.1.3

\section{INTRODUCTION}

The medical devices are crucial components of patient care. ${ }^{1,2}$ They may be uncomplicated devices employed during medical examinations, such as tongue depressors and thermometers, or sophisticated life-saving implants like heart valves and coronary stents. ${ }^{1}$ As per GHTF harmonized definition, the term "medical device" means any instrument, apparatus, implement, machine, appliance, implant, in vitro reagent or calibrator, software, material or other similar or related article intended by the manufacturer to be used, alone or in combination, for human beings for one or more of the specific purpose(s) of diagnosis, prevention, monitoring, treatment or alleviation of disease or diagnosis, monitoring, treatment, alleviation of or compensation for an injury or investigation, replacement, modification, or support of the anatomy or of a physiological process or supporting or sustaining life or control of conception or disinfection of medical devices or providing information for medical or diagnostic purposes by means of in vitro examination of specimens derived from the human body; and which does not achieve its primary intended action in or on the human body by pharmacological, immunological or metabolic means, but which may be assisted in its intended function by such means. ${ }^{1,4}$

Previously in many countries medical device regulations rarely existed and there were limited regulatory controls to prohibit the use of low quality devices. ${ }^{2,3}$ Hence there was a compulsion to draft regulatory policies on medical devices to assess their quality, safety and efficacy. ${ }^{2}$ Fortunately since the early 1980s, the regulatory paradigm for medical devices has changed exceptionally. ${ }^{4}$ Now with the availability of different regulations of the countries or region on medical devices, there is a need to harmonize regulations in order to curtail regulatory hurdles and expedite access to high quality, safe and efficacious medical devices. ${ }^{5}$ With this background in mind, first various regulations of medical devices across major economies of the world will be reviewed and then other pertinent issues of medical device regulations will be discussed.

\section{UNITED STATES}

In the United States, the Federal Food Drug and Cosmetic Act regulate the medical device. The marketing application must be filed with the Food and Drug Administration (FDA) and approval received before marketing the medical device in the United States. ${ }^{6}$ Within FDA, the Center for Devices and Radiological Health (CDRH) is primarily accountable for pre- and postmarket supervision of medical devices in the United States. ${ }^{7}$ The United States has adopted a risk-based classification for medical devices wherein the devices are classified according to the risk associated with the use of the device. ${ }^{6}$ Devices are classified into a 3-tiered system (Class I-lowest risk; Class II-intermediate risk; Class IIIhighest risk). ${ }^{8}$

\section{Class I devices}

These are devices that do not lead to a likely preposterous hazard of patient ailment or injury. Class I devices (lowest risk) are regulated with general controls, which are well-accepted norms related to labeling, manufacturing, post-market surveillance, and reporting. Devices are assigned class I status when there is a plausible surety that general controls alone will be sufficient to guarantee safety and effectiveness. Moreover, countermeasures such as seizure, recall prerogative etc have been granted to the FDA. Formal FDA scrutiny is not needed for most class I devices before their market launch. The FDA does not evaluate these products separately nor is there a requirement that safety and effectiveness of the individual product be confirmed before launch. Some examples of products in class I category are handheld surgical instruments, tongue depressors and crutches etc. ${ }^{8-10}$

\section{Class II devices}

Class II devices are those higher-risk devices for which only general controls are inadequate to establish safety and effectiveness, and for which there are sufficient data to substantiate special controls. Because these devices pose a greater risk of harm compared to class I devices and hence they are bound by added regulation of special controls, which may be confirmed by the FDA. Also, the majority of class II devices need FDA 
clearance of a premarket notification $510(\mathrm{k})$ process before the device is launched. In the $510(\mathrm{k})$ process, the medical device manufacturer must submit data to prove that the new device is comparable to a legally marketed device. Even though this can generally be corroborated based on the bench and animal testing alone, very few 510(k) applications need to submit clinical data. Generally, this class of device includes hightechnology products such as cardiac monitors, tampons, infusion pumps, surgical drapes and oxygen masks. ${ }^{8,9}$

\section{Class III devices}

The class III devices are those which are either life-sustaining/supporting or of considerable importance in averting impairment of human health. Examples of class III devices are pacemakers, heart valves, coronary stents etc. Because they are judged to pose the highest potential risk of illness or injury, hence, general and special controls alone are insufficient to establish safety and effectiveness. Therefore, most class III devices need premarket approval (PMA) from FDA before they can be launched. ${ }^{8}$

\section{Humanitarian use devices}

Humanitarian use devices (HUDs) are marketed for a limited population in an entirely separate process termed a Humanitarian Device Exemption (HDE). HUD has been discussed in detail in the below mentioned paragraphs on HDE. ${ }^{7}$ Now let us discuss premarket notification $510(\mathrm{k})$ process, PMA Process and HDE.

\section{What is premarket notification $510(\mathrm{k})$ process?}

A $510(\mathrm{k})$ is a premarket submission made to the FDA to establish that the device to be marketed is safe and effective. Most class II devices need pre-market entry notification (termed $510 \mathrm{k}$ ). This is basically a regulatory review process which is less rigorous compared to the PMA process. The $510 \mathrm{k}$ submission must prove that the new device is comparable to an already marketed device in the United States. It is the duty of the sponsor to ascertain a suitable device to which they need to demonstrate that their new device is comparable. Before marketing clearance, the manufacturer must also ensure that the device is adequately labeled in accordance with FDA's labeling requirements. Most device applications cleared under the $510(\mathrm{k})$ process are on the basis of preclinical testing only. Sometimes when there are apprehensions regarding safety and effectiveness, the FDA can demand clinical data for $510(\mathrm{k})$ clearance. ${ }^{6,7,11}$

\section{What is PMA process?}

PMA is a process of review to assess the safety and efficacy for all class III devices. This is the most rigorous regulatory procedures for medical devices. ${ }^{6}$ As discussed above, because Class III devices are either lifesustaining/supporting or of considerable importance in averting impairment of human health, hence the PMA process requires clinical study to demonstrate the safety and effectiveness prior to marketing approval. Due to the level of risk associated with Class III devices, FDA has determined that general and special controls alone are insufficient to assure the safety and effectiveness of class III devices. Therefore, these devices require a PMA application under section 515 of the FD\&C Act in order to obtain marketing clearance. PMA is the most stringent type of device marketing application required by FDA. The applicant must receive FDA approval of its PMA application prior to marketing the device. PMA approval is based on a determination by FDA that the PMA contains sufficient valid scientific evidence to assure that the device is safe and effective for its intended use(s). An approved PMA is, in effect, a private license granting the applicant (or owner) permission to market the device. FDA regulations provide 180 days to review the PMA and make a determination. The regulation governing premarket approval is located in Title 21 Code of Federal Regulations (CFR) Part 814, Premarket Approval. A class III device that fails to meet PMA requirements is considered to be adulterated under section 501(f) of the FD\&C Act and cannot be marketed. ${ }^{7,12}$

\section{What is HDE?}

HUDs are marketed for a small population through an entirely separate regulatory process called as HDE. HDE is a regulatory pathway to allow for marketing approval of class III devices meant for small markets. In contrast to the PMA, a HUD designation requires that less than 4000 patients in the United States each year are eligible for use of the device under the proposed indications. ${ }^{8}$ After granting of an HUD designation, the device must receive an $\mathrm{HDE}$ for approval of the intended use. Unlike a PMA approval, under HDE, the sponsor is not expected to submit clinical data to prove safety and efficacy. But they must submit sufficient data proving that the device does not pose unacceptable risks and that the probable benefit of device outweighs the risks. Finally, the sponsor must establish that no similar devices are available to treat or diagnose the particular disease or condition, and that the device could not be introduced into the market without HUD designation. A device approved under an HDE, however, remains as an investigational device committed to the specific indications stated in the product labeling. Hence, investigators are compelled to get permission from their Institutional Review Boards for use of the device in each case. ${ }^{7}$ Two examples of devices given marketing approval through HDE are the Argus II Retinal Prosthesis System meant for patients of 25 years or more with minimal or no light perception vision due to advanced retinitis pigmentosa and Berlin Heart EXCOR Pediatric Ventricular Assist Device (VAD) meant for pediatric patients with severe isolated left ventricular or biventricular dysfunction needing a cardiac transplant and circulatory support. ${ }^{13}$

\section{Post-market surveillance}

In addition to its role in the evaluation of new devices, the FDA/CDRH charter includes the regulation of devices after approval. This function has been carried out primarily by the Medical Device Reporting (MDR) program. Since 1984, medical device manufacturers and importers have been required to have processes in place to respond and report to the FDA any device-related deaths, serious injuries, or certain malfunctions. The Safe Medical Devices Act of 1990 required user facilities to report device-related deaths directly to the FDA as well to the manufacturer. In addition, the user facility is required to notify the manufacturer of nonlethal events, including serious device-related injuries and malfunctions. The FDA actively maintains a database, which summarizes all medical device reports it receives. In addition to the MDR system, the FDA/CDRH has the power to mandate a more formal post-market surveillance program for certain devices, including permanent implants like pacemakers and stents or life-sustaining devices like left ventricular assist devices. These programs primarily focus on morbidity and mortality and the impact of a device failure. On device approval, the FDA notifies the manufacturer that it is subject to post-market surveillance. The manufacturer must submit to the FDA/CDRH a post-marketing surveillance program within 30 days after market launch. Post-market surveillance is part of evaluating the safety and effectiveness of medical devices. ${ }^{14}$

\section{EUROPEAN UNION}

Medical Device Directive (MDD) regulates the safety and marketing of medical devices in Europe since 1990s. In contrast to the United States, the European Union (EU) follows a four-class scheme. Devices are classified into class I (including Is and Im), IIa, IIb, and III. Class III are ranked as the highest and higher the classification the greater the level of scrutiny. Medical devices cannot be marketed in the European Union without adhering to the stringent regulations of the European Union; one of these regulations is the affixation of the Conformite "Europe" enne (CE) marking. ${ }^{15}$ 


\section{CE marking}

Medical device manufacturers need to exhibit CE marking on their products in order to ensure that devices are safe and fit for their intended use. ${ }^{12}$ All medical devices in Europe must have the conformity mark CE before they can be marketed. It is seen as a proclamation by the manufacturer that the device fulfills all the earmarked provisions of the pertinent regulation. This comprises those corresponding to safety and it proves that, where needed, the device has been evaluated as per the relevant procedures. The CE mark also guarantees that the product can be freely marketed all over EU without additional control. ${ }^{15} \mathrm{CE}$ marking is carried out by the EU-accredited private organisations known as notifying bodies (NBs). A manufacturer needs to pick a notified body to grant certification of a new device for CE marking. The notified body will seek certain materials (e.g., a literature review), based on the device class, and appraise the manufacturer's conformity to the underlying requirements mentioned in each directive. ${ }^{12} \mathrm{NBs}$ have been discussed in detail below.

Devices of classes II and III, and devices of class I with either measuring function or sterility requirements, must put forward following information to the regulator: (1) a Declaration of Conformity to the appropriate EU Directives; and (2) particulars of the conformity assessment plan followed. Also, for higher risk class devices that need design examination or type examination, the relevant $\mathrm{CE}$-Certificates provided by a notified body need to be given to the concerned authority. Other medical devices of class I are not subject to pre-market submissions, even though they must obey the requisite propositions of safety and efficacy in their design, construction and labelling obligations. ${ }^{5}$

\section{What is NBs?}

The NBs are autonomous private-enterprise to enact regulatory control over medical devices in the European Union. NBs have the authority to grant the CE mark, the formal marking essential for certain medical devices. NBs are nominated, observed, and appraised by the relevant member states through the national competent authorities. Most of the functions accomplished by the FDA/CDRH in the United States are done by NBs in EU. Such functions are certification of medical device, designation of device type, quality systems assessment and verification, and design dossiers review for high-risk devices. Medical device companies have the right to select any notified body nominated to cover the particular class of device under review. After approval, post-marketing surveillance is the authority of the member state via the competent authority. NBs typically function in an enterprising manner which leads to contrast as well as competition among NBs. NBs are considered by industry as an organization with quick and efficient response due to fewer hurdles caused by red-tape. ${ }^{8}$

Table 1 compares salient features of medical device regulations of US and EU.

\section{JAPAN}

In Japan, the Pharmaceuticals Medical Devices Agency (PMDA), a regulatory agency founded in 2004, analyses, assesses and suggests decisions to the Ministry of Health, Labor and Welfare (MHLW), but it has no jurisdiction to take eventual decisions. MHLW is a powerful central ministry amalgamating political authorization and accountability for the whole medical device regulatory scheme, in addition to the national health protection system, public health, medical facilities and labor and welfare matters. ${ }^{16}$ In 2005 a new law was introduced which was harmonized with international stipulations. The law is known as the New Pharmaceutical Affairs Law (PAL). The main difference with international stipulations is that Japan has additional needs for buildings and manufacturing spaces. A manufacturer must work as per the Market Authorization Holder (MAH) process. In this process the manufacturer is only accountable for production and the MAH is accountable for the launch of the product to the market. ${ }^{3}$

In Japan, medical devices are classified into General Medical devices (Class I), Controlled Medical Devices (Class II) and Specially Controlled Medical Devices (Class III and IV). A manufacturer must also get a device notification, device certificate or device approval based on the class of device. Medical devices in class I need a device notification, medical devices in class II need a device certificate and medical devices class III and IV need a device approval. Clinical trials are not required for class I, in principle not necessary for class II, sometimes necessary for class III and in principle compulsory for class IV. In Japan it is compulsory to follow Good Vigilance Practice (GVP). ${ }^{3}$

\section{AUSTRALIA}

In Australia, the medical devices are regulated by the Therapeutic Goods Administration (TGA). Before being launched in the Australian market the medical devices must be recorded in the database of the Australian Register of therapeutic Goods (ARTG). In Australia, medical devices are classified into following classes; class I, class I- supplied sterile, class I- incorporating a measuring device, class IIa, class IIb, class III and Active Implantable Medical devices (AIMD). ${ }^{3,17,18}$ Class I pose a minimum risk whereas class I- supplied sterile, class I- incorporating a measuring device and class IIa poses low medium risk. Class IIb represents medium high risk whereas and class III and Active Implantable Medical devices the highest risk. There is a distinct classification system for In vitro Diagnostic medical devices (IVDs). A manufacturer has to prove that both the device and manufacturing process used to make the device adhere to the requirement of the therapeutic good legislation under conformity assessment of medical device. The certificate granted by the regulatory body proving that a manufacturer has been assessed and has the proper system in place to manufacture the device is known as conformity assessment evidence. A conformity assessment certificate, a Declaration of Conformity and an application to include the medical device in the ARTG are the three documents essential to register a medical device in Australia., ${ }^{3,17}$

\section{CANADA}

The medical device is classified based on the Canadian Risk-Based Classification System (RBCS), under the aegis of the Therapeutic Products Division (TPD) of Health Canada. Alike European Union, Health Canada has adopted a four-tier classification system for medical devices based on their risk to the human body. Class I pose the lowest risk to the human body and Class IV poses the highest risk. Because Health Canada employs a risk-based process for the regulation of medical devices, the scrutiny increases with the risk of the device. Class I devices are reckoned to be lower risk device and post market monitoring is adjudged to be enough. Class II devices are licensed and are subject to the safety and efficacy needs of the regulations. In addition, manufacturers must acquire a valid Quality Systems certification, along with the post market controls. The higher risk devices of Class III and IV have the added obligations and must fulfill the regulatory prerequisites of a premarket safety and efficacy assessment. ${ }^{19}$

Table 2 compares salient features of regulations of Japan, Australia and Canada.

\section{BRAZIL}

The new regulation on GMP - Good Manufacturing Practices inspections for medical devices was announced as per Resolution RDC 16, of March 2013. This regulation integrated the regulations for both medical devices and IVD device. In August 2013, the National Health Surveillance Agency (ANVISA) announced RDC 39/2013. This resolution 
Table 1: compares salient features of medical device regulations of US and EU.

\begin{tabular}{|c|c|c|}
\hline & United States & EU \\
\hline Regulation of medical device & $\begin{array}{l}\text { The Federal Food Drug and Cosmetic } \\
\text { Act }\end{array}$ & Medical Device Directive (MDD) \\
\hline $\begin{array}{l}\text { Pre- and postmarket supervision of } \\
\text { medical devices }\end{array}$ & $\begin{array}{l}\text { Within FDA, the Center for Devices and } \\
\text { Radiological Health (CDRH) is primarily } \\
\text { accountable }\end{array}$ & $\begin{array}{l}\text { The NBs are autonomous private- } \\
\text { enterprise to enact regulatory control over } \\
\text { medical devices. NBs have the authority to } \\
\text { grant the CE mark. }\end{array}$ \\
\hline Risk classification & $\begin{array}{l}\text { Three-tiered system (Class I-lowest risk; } \\
\text { Class II-intermediate risk; Class III- } \\
\text { highest risk) }\end{array}$ & $\begin{array}{l}\text { Four-class scheme (Class I (including Is } \\
\text { and Im), IIa, IIb, and III) }\end{array}$ \\
\hline Approval system & $\begin{array}{l}\text { Class I device: general controls } \\
\text { Class II devices : premarket notification } \\
\text { 510(k) process class III devices need } \\
\text { premarket approval (PMA) }\end{array}$ & $\begin{array}{l}\text { Medical device manufacturers need to } \\
\text { exhibit CE marking on their products in } \\
\text { order to ensure that devices are safe and fit } \\
\text { for their intended use }\end{array}$ \\
\hline
\end{tabular}

Table 2: Salient features of regulations of Japan, Australia and Canada

\begin{tabular}{|c|c|c|c|}
\hline & Japan & Australia & Canada \\
\hline $\begin{array}{c}\text { Pre- and postmarket } \\
\text { supervision of medical } \\
\text { devices }\end{array}$ & $\begin{array}{l}\text { Pharmaceuticals Medical } \\
\text { Devices Agency (PMDA), }\end{array}$ & $\begin{array}{l}\text { The Therapeutic Goods } \\
\text { Administration (TGA). }\end{array}$ & $\begin{array}{l}\text { Therapeutic Products Division } \\
\text { (TPD) of Health Canada. }\end{array}$ \\
\hline Risk classification & $\begin{array}{c}\text { General Medical devices } \\
\text { (Class I), Controlled Medical } \\
\text { Devices (Class II) and Specially } \\
\text { Controlled Medical Devices } \\
\text { (Class III and IV). }\end{array}$ & $\begin{array}{c}\text { class I, class I- supplied } \\
\text { sterile, class I- incorporating } \\
\text { a measuring device, class IIa, } \\
\text { class IIb, class III and Active } \\
\text { Implantable Medical devices } \\
\text { (AIMD) }\end{array}$ & $\begin{array}{l}\text { Four-tier classification (Class I } \\
\text { pose the lowest risk and Class } \\
\text { IV poses the highest risk). }\end{array}$ \\
\hline Approval system & $\begin{array}{c}\text { Class I need a device } \\
\text { notification; class II need a } \\
\text { device certificate; class III and } \\
\text { IV need a device approval. }\end{array}$ & $\begin{array}{l}\text { A manufacturer has to prove } \\
\text { that both the device and } \\
\text { manufacturing process used to } \\
\text { make the device adhere to the } \\
\text { requirement of the therapeutic } \\
\text { good legislation }\end{array}$ & $\begin{array}{l}\text { Class I devices: only post } \\
\text { market monitoring. Class II } \\
\text { devices: safety, efficacy, quality } \\
\text { and the post market control; } \\
\text { Class III and IV: premarket } \\
\text { safety and efficacy assessment }\end{array}$ \\
\hline
\end{tabular}

encompasses administrative procedures for Brazilian Good Manufacturing Practice (BGMP) permission, including those needing BGMP compliance for each product line. A different presidential order (Decree No. 8077/2013) advocates that in the future, ANVISA may adopt a more selective approach in deciding which medical devices need BGMP certification and which do not require such certification. Such a move could expedite the regulatory pathway for lower-risk devices. ${ }^{20}$

\section{RUSSIA}

The Russian regulation of medical devices is intricate and includes a number of different regulatory authorities. Roszdravnadzor (Federal Service on Surveillance in Healthcare and Social Development) is the expert authority accountable for registration and assessing clinical safety and efficacy of all medical devices. GOST Standard (Federal Agency for Technical Regulation and Metrology) ensures that all medical devices fulfill well-established Russian benchmarks. A GOST-R quality certificate is needed for importing any medical device into Russia. A SanitaryEpidemiology Conclusion (Hygiene Certificate) is also needed before any medical device can be imported into Russia. Rospotrebnadoz (Federal Service for Supervision in the Area of Consumer Rights and Welfare Protection) is make sure that all medical devices related with the human body, or which in other ways may adversely affect patients or doctors, fulfill sanitary and epidemiological standards. Russia applies a risk based system for classifying medical devices into four classes (Class 1, $2 \mathrm{a}, 2 \mathrm{~b}$, and 3 ). The class 1 is the lowest risk device and class 3 the highest risk device. ${ }^{6,20}$

\section{INDIA}

The Central Drug Standards Control Organization (CDSCO) which is a part of the Ministry of Health and Family Welfare currently regulates medical devices in India. In 2006, Medical Devices Regulation Bill (MDRB) was introduced with the aim to strengthen laws related to medical devices and institute the Medical Device Regulatory Authority of India (MDRA). The purpose of the bill was to create and sustain a national system of controls for the quality, safety and accessibility of medical devices in India. However, till now the above Bill has not been approved by the Parliament. Currently, actions related to medical devices are governed by the Drugs and Cosmetics Act, 1940 and Rules, 1945. Most recently in August, 2013, the Drugs and Cosmetics (Amendment) Bill, 2013 was introduced. Among the other things, this bill also includes a separate chapter for regulatory measures for import, manufacture, sale, distribution and export of medical devices in India. For the purpose of import of medical devices in India, the procedure for registration and import license as prescribed under the Drugs and Cosmetics Rules shall be followed. Imported medical devices on the notified list that have already obtained approval in the United States (by the FDA) or the European Union (by CE Marking) are allowed on the Indian market without undergoing separate conformity assessment procedures. ${ }^{21,22}$

\section{CHINA}

The Chinese medical device regulatory pathway is very convoluted. Albeit in 2013, China Food and Drug Administration (CFDA) took 
some major steps such as electronic validation, new approval regulations for innovative devices, and exclusions from China Compulsory Certification (CCC) Mark demands. Through new online system medical device registrants can solicit regulatory validation of their device classifications. Under new approval regulations for innovative devices, qualifying medical device products would be given preference review by the CFDA. But qualifying medical devices must be produced in China and must be the unique device to be registered in China. ${ }^{20}$

\section{THE WAY FORWARD: HARMONIZATION OF MEDICAL DEVICE REGULATIONS}

The regulations for approval of a medical device must be harmonized in order to give the medical device industry a chance to fully accomplish its prospects. ${ }^{4,16}$ With this purpose in sight, in 1993 the Global Harmonization Task Force (GHTF) was initiated. The founding member countries of the GHTF are the European Union, Japan and the United States, together with Canada and Australia. ${ }^{5}$ The major objective of the GHTF is to integrate and harmonize regulatory processes through different GHTF Study Groups. The GHTF also encourages cutting edge technologies and simplifies international trade. The key step by which its objectives are achieved is through the preparation and issuing of harmonized regulatory guidance's. These guidance's, prepared by different GHTF Study Groups, can then be enacted by member national regulatory authorities or others. ${ }^{5}$ The participation of developing countries in GHTF is via their regional groups, the Asian Harmonization Working Party (AHWP), and the Latin America Harmonization Working Party (LAHWP), respectively. The involvement of the developing countries in these forums, added to guidance documents issued by GHTF will be critical in creating harmonized regulatory processes for medical devices across the world. The GHTF's Study Group has published guidance on medical device classification principles. The guidance recommends a four-class system for medical devices based on intended use, and that should determine conformity assessment pathways for individual devices. The guidance provides 17 rules for classification of devices, as well as decision trees demonstrating how to apply the rules. Structural recommendations of the GHTF's classification rules include a four-tier system with Class A representing lowest-hazard devices and Class $\mathrm{D}$ the highest-hazard devices. It further states that classification determinations should be based on a device's potential to harm a patient, its intended use and also the technology it uses and classification rules should be able to accommodate future technology developments. Manufacturers should document their justifications for assigning their devices to Class A, B, C or D. ${ }^{16,23}$

\section{MEDICAL DEVICE REGULATION: IS IT TIME TO SCRUTINIZE IT?}

There has been increased recall of medical device in recent times. ${ }^{12}$ There are certain regulatory issues which need to be addressed as far as medical device regulations are concerned apart from the harmonization of the device regulations. Those issues have been summarized below.

\section{Correct classification of the devices}

The available data indicate that the majority of the recalled medical device was not classified as high risk at the time of regulatory approval and sometimes they were excluded from a detailed review process because they were considered to be low risk device. Thus the wrong classification of the device might put the life of the patient at danger. ${ }^{11,24}$

\section{Substantial data to assess the safety and efficacy of medical device}

Dhruva and Redberg have emphasized the paramount importance of having substantial data on safety and efficacy to do risk benefit assessments of the device. ${ }^{24}$

\section{More transparency in the review process}

There should be more transparency about the data based on which regulatory bodies grant approval for the medical device. It will help in assessing the quality of data used for medical device approval. ${ }^{25}$

\section{Emphasis on post-marketing evaluation studies}

Continued pooling of post marketing surveillance data will generate exhaustive database about the safety and efficacy of the device in a large number of patients. ${ }^{26,27}$

\section{Streamlining the regulatory process for medical devices}

The complexity, unpredictability, delay and excessive process in medical device review and approval can increase the cost of medical device. Regulators should streamline the regulatory processes to eliminate unnecessary costs and barriers. Streamlining will lead to an accelerated approval process for medical devices leading to considerable savings in time and money and facilitate development of affordable and innovative medical devices. ${ }^{28}$

\section{CONCLUSION}

The regulation of medical devices around the world is very diverse. There has been an upsurge in the number, diversity, and intricacy of medical devices in last two decades. Regulation of these devices has also advanced due to the requirement for a steady regulatory perspective. ${ }^{6}$ Most countries are trying to harmonize the regulatory guidelines for medical devices through their participation in GHTF. The endowments of GHTF, Latin American Harmonization Working Party LAHWP and Asian Harmonization Working Party (AHWP), will play an important role in the harmonization of regulatory guidelines of medical devices. ${ }^{15}$ After taking into consideration all the above mentioned facts, we can conclude that harmonized regulation of medical device will lead to the availability of quality product. Non-harmonization of medical device regulation might lead to serious concerns. ${ }^{4}$ Another issue is increased recall of medical device in recent times. ${ }^{12}$ Some studies in public domain illustrate that regulatory reforms are required to promote high quality evidence in approval of higher risk devices. ${ }^{24,25}$

\section{ACKNOWLEDGEMENT}

None.

\section{CONFLICT OF INTEREST}

The author declares none.

\section{SUMMARY}

- The regulation of medical devices around the world is very diverse. There has been an upsurge in the number, diversity, and intricacy of medical devices in last two decades.

- Most countries are trying to harmonize the regulatory guidelines for medical devices through their participation in GHTF.

- Harmonized regulation of medical device will lead to the availability of quality product.

- Some studies in public domain illustrate that regulatory reforms are required to promote high quality evidence in approval of higher risk devices. 


\section{ABBREVIATIONS USED}

GHTF: Global Harmonization Task Force; FDA: Food and Drug Administration; CDRH: Center for Devices and Radiological Health; PMA: Premarket approval; HUDs: Humanitarian use devices; HDE: Humanitarian Device Exemption; CFR: Code of Federal Regulations; VAD: Ventricular Assist Device; MDR: Medical Device Reporting; MDD: Medical Device Directive; EU: European Union; CE: Conformite "Europe" enne; NBs: Notifying Bodies; PMDA: Pharmaceuticals Medical Devices Agency; MHLW: Ministry of Health, Labor and Welfare; PAL: Pharmaceutical Affairs Law; MAH: Market Authorization Holder; GVP: Good Vigilance Practice; TGA: Therapeutic Goods Administration; ARTG: Australian Register of therapeutic Goods; AIMD: Active Implantable Medical devices; IVD: In vitro Diagnostic; RBCS: Risk-Based Classification System; TPD: Therapeutic Products Division; GMP: Good Manufacturing Practices; BGMP: Brazilian Good Manufacturing Practice; CDSCO: Central Drug Standards Control Organization; MDRB: Medical Devices Regulation Bill; MDRA: Medical Device Regulatory Authority; CFDA: China Food and Drug Administration; CCC: China Compulsory Certification; AHWP: Asian Harmonization Working Party; LAHWP: Latin America Harmonization Working Party.

\section{ABOUT AUTHOR}

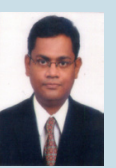

Dr Sandeep Kumar Gupta is a pharmacologist with approximately 8 years of experience in both academics and industry. He received my MD (Pharmacology) from RIMS, Ranchi in 2007 and started his career in Ranbaxy Research Lab (Gurgaon, India) as Senior Research Scientist. He is currently working as Assistant Professor in the Department of Pharmacology in DSMCH, Permabalur (Tamilnadu, India). He is a life member of the Indian Pharmacological Society. He has published about 12 papers in peer-reviewed and Pubmed-indexed journals. He has also written chapters in books titled Fundamentals of Clinical Trial \& Research (Paras Publication), Molecular Vaccines: From Prophylaxis to Therapy-Volume 2 (Springer Publication) and Advances in collating and using trial data (Future Publication).

\section{REFERENCES}

1. Johnson JA. FDA Regulation of Medical Devices. CRS Report for Congress Prepared for Members and Committees of Congress. June 25, 2012. Available from: URL: http: //www.fas.org/sgp/crs/misc/R42130.pdf on 9th April 2014.

2. Jardaneh M, Al-Titi N, Shaqlous R, Kawar R. Medical Devices: Regulations \& requirements in Europe, USA, Jordan \& Saudi Arabia. October 2010. Available from: URL: http: //sipsmena.com/wp-content/uploads/2013/01/Medical-DevicesRegulations-requirements-in-Europe-USA-Jordan-Saudi-Arabia.pdf on 9th April 2014

3. Brolin S. Global Regulatory Requirements for Medical Devices. 2008. Available from: URL: http: //mdh.diva-portal.org/smash/get/diva2: 121327/FULLTEXT01. pdf on 10 April 2014.

4. Kaushik A, Saini K, Anil B, Rambabu S. Harmonized Medical Device Regulation: Need, Challenges, and Risks of not Harmonizing the Regulation in Asia. J Young Pharm. 2010; 2(1): 101-6.

5. World Health Organization Geneva. Medical device regulations: Global overview and guiding principles. 2003. Available from: URL: http: //www.who.int/ medical_devices/publications/en/MD_Regulations.pdf on 12th April 2014

6. Lamph S. Regulation of medical devices outside the European Union. J R Soc Med. 2012; 105 Suppl 1: S12-21.

7. Peña C, Li K, Felten R, Ogden N, Melkerson M. An example of US Food and Drug Administration device regulation: medical devices indicated for use in acute ischemic stroke. Stroke. 2007; 38(6): 1988-92.

8. Kaplan AV, Baim DS, Smith JJ, Feigal DA, Simons M, Jefferys D, Fogarty TJ, Kuntz RE, Leon MB. Medical device development: from prototype to regulatory approval. Circulation. 2004; 109(25): 3068-72.

9. Smith JJ, Jensen ME, and Dion JE. FDA medical device regulation and informed consent. AJNR. 1998; Vol Isuue ?? 1815-8. Available from: URL: http: // www.ajnr.org/content/19/10/1815.full.pdf on 5th May 2014

10. Monsein LH. Primer on medical device regulation. Part II. Regulation of medical devices by the U.S. Food and Drug Administration. Radiology. 1997; 205(1): 10-8.

11. Zuckerman DM, Brown P, Nissen SE. Medical device recalls and the FDA approval process. Arch Intern Med. 2011; 171(11): 1006-11.

12. Heneghan C, Thompson M, Billingsley M, Cohen D. Medical-device recalls in the UK and the device-regulation process: retrospective review of safety notices and alerts. BMJ Open. 2011; 1(1): e000155.

13. U.S. Food and Drug Administration (FDA). Listing of CDRH Humanitarian Device Exemptions. Available from: URL: http: //www.fda.gov/MedicalDevices/ ProductsandMedicalProcedures/DeviceApprovalsandClearances/HDEApprovals/ucm161827.htm on 31st July 2014.

14. Mehran R, Leon MB, Feigal DA, Jefferys D, Simons M, Chronos N, et al. Postmarket approval surveillance: a call for a more integrated and comprehensive approach. Circulation. 2004; 109(25): 3073-7.
15. French-Mowat E, Burnett J. How are medical devices regulated in the European Union? J R Soc Med. 2012; 105(Suppl 1): S22-8.

16. Altenstetter $\mathrm{C}$. Global and local dynamics: the regulation of medical technologies in the European Union, Japan and the United States. Presented to panel 6E Context and Regulatory Design, Third Biennial Conference "Regulation in the Age of Crisis", June 17-19, 2010, Dublin, Ireland, Stream: Social Regulation. Sponsored by the ECPR Regulatory Governance Standing Group. Available from: URL: http: //paperroom.ipsa.org/papers/view/422

17. Australian regulatory guidelines for medical devices (ARGMD). Version 1.1 May 2011. TGA Health Safety Regulation. Available from: URL: http: //www.tga.gov. au/pdf/devices-argmd-01.pdf on 19th June 2014

18. Schuh JC. Medical device regulations and testing for toxicologic pathologists Toxicol Pathol. 2008; 36(1): 63-9.

19. Health Canada. Canada Medical Device Regulation, 2011. Available from: URL: http: //laws-lois.justice.gc.ca/eng/regulations/sor-98-282/

20. Hartford J. The Global Medical Device Regulatory Environment. Regulatory and Compliance November 2013. Available from: URL: http: //www.mddionline. com/article/global-medical-device-regulatory-environment on 5th May 2014

21. Singh RS, Mudoi M. India: The Drugs And Cosmetics (Amendment) Bill, 2013 Regulations For Medical Devices And Conduct Of Clinical Trial. September 2013. Available from: URL: http: //www.mondaq.com/india///264918/food drugs law/The Drugs And Cosmetics Amendment Bill 2013 Regulations For Medical Devices And Conduct Of Clinical Trial on 16th June 2014

22. Radhadevi N, Balamuralidhara V, Pramod Kumar TM, Ravi V. Regulatory guidelines for medical devices in India: An overview. Asian J of Pharms. 2012; 6(1): 10-7.

23. The Global Harmonization Task Force Study Group 1. Principles of Medical Devices Classification. June 27, 2006. Available from http://www.imdrf.org/ docs/ghtf/final/sg1/technical-docs/ghtf-sg1-n15-2006-guidance-classification060627.pdf on 4th October 2015.

24. Dhruva SS, Redberg RF. Medical device regulation: time to improve performance. PLoS Med. 2012; 9(issue ?): e1001277.

25. 25. Kramer DB, Xu S, Kesselheim AS. How does medical device regulation perform in the United States and the European union? A systematic review. PLoS Med. 2012; 9(7): e1001276.

26. 26. Garber AM. Modernizing device regulation. N Engl J Med. 2010; 362(13): 1161-3.

27. 27. Polisena J, Jutai J, Chreyh R. A proposed framework to improve the safety of medical devices in a Canadian hospital context. Med Devices (Auckl). 2014 7 (issue ?): 139-47.

28. 28. Kaplan AV, Williams DO. Medical device regulatory landscape: the imperative of finding balance. Circ Cardiovasc Interv. 2012; 5(1): 2-5. 